\title{
Retrieval of River Ice Thickness From C-Band PolSAR Data
}

\author{
Stephane Mermoz, Sophie Allain-Bailhache, Monique Bernier, Senior Member, IEEE, \\ Eric Pottier, Fellow, IEEE, Joost J. Van Der Sanden, and Karem Chokmani
}

\begin{abstract}
River ice has an important effect on natural processes and human activities in northern countries. Current models for estimating river ice thickness are mostly based on environmental data. They require several inputs and yield only a global estimate of ice thickness for a large heterogeneous area. Attempts have been made intending to retrieve river ice thickness from remote sensing using monopolarized $\mathrm{C}$-band radar data. No reliable maps of ice thickness have been produced. In this paper, the potential of polarimetric synthetic aperture radar (PolSAR) data for estimating river ice thickness is demonstrated, and a river ice thickness retrieval model is proposed. The $\mathrm{C}$-band SAR images used in this paper were acquired by Radarsat-2 in the winter of 2009 over the Saint-François River (Southern Quebec), the Koksoak River (Northern Quebec), and the Mackenzie River (Northwest Territories) in Canada. Field campaigns were carried out to obtain ice thickness validation data at $\mathbf{7 0}$ locations. Polarimetric entropy was used to obtain ice thickness estimates. This approach results in spatially distributed ice thickness maps for selected ice types.
\end{abstract}

Index Terms-Polarimetric synthetic aperture radar (PolSAR), river ice, thickness retrieval.

\section{INTRODUCTION}

$\mathbf{R}$ IVER ice has an important effect on natural processes and human activities in northern countries such as Canada. Information on river ice cover supports science, engineering, and management activities, including hydraulic modeling, ice breakup forecasting, ice road routing, infrastructure design, industrial water control, and ice hazard management. River ice cover variables of interest typically include coverage, type, thickness, and condition. In this paper, the focus is on the most challenging variable, i.e., ice thickness. Existing models for retrieving river ice thickness are mostly local estimators based on environmental data [1]-[3]. They require many inputs and provide only one global value of ice thickness for a large heterogeneous area. Synthetic aperture radar (SAR) satellite offer considerable potential in support of river ice monitoring [4]-[7]. SAR achieves relatively fine resolution and operates in the microwave range of the electromagnetic spectrum. This

Manuscript received April 19, 2012; revised October 20, 2012 and March 21 2013; accepted May 13, 2013. Date of publication July 17, 2013; date of current version March 3, 2014.

S. Mermoz was with the National Institute of Scientific Research, Quebec, QC G1K 9A9, Canada. He is now with the Center for the Study of the Biosphere from Space (CESBIO), 31401 Toulouse, France.

S. Allain-Bailhache and E. Pottier are with the University of Rennes 1, 35065 Rennes, France.

M. Bernier and K. Chokmani are with the National Institute of Scientific Research, Quebec, QC G1K 9A9, Canada.

J. J. Van Der Sanden is with the Canada Center of Remote Sensing, Natural Resources Canada, Ottawa, ON K1A 0E8, Canada.

Digital Object Identifier 10.1109/TGRS.2013.2269014 enables imaging at any time of day or night. Numerous studies have addressed the potential of SAR for the mapping of sea ice and/or retrieval of sea ice thickness [8]-[13]. Studies using single-polarized C-band SAR data for the mapping of river ice thickness have yielded mixed results [14], [15] and concluded that there may be potential for SAR images to provide ice thickness information at coarse resolution [15]. The purpose of this investigation is to explore the potential of Radarsat-2 (with a repeat cycle of 24 days) polarimetric SAR (PolSAR) data for the mapping of river ice thickness, through a detailed analysis involving an extensive field program on three rivers in Canada. PolSAR data enable the computation of variables, such as entropy, that capture variability in terms of scattering mechanisms [16]. The information content of these variables with respect to ice thickness is evaluated and demonstrated in this paper. The following section provides background information on the characterization of river ice. Section III introduces the available radar and validation data. Section IV describes existing models, and Section V discusses results.

\section{Physical and Electromagnetic CHARACTERISTICS OF RIVER ICE}

The different forms and characteristics of river ice are described in order to understand better their various backscatter signatures.

\section{A. River Ice Types}

Thermal ice forms when stream flow is slow, and the water is calm [17]. This ice is usually solid and pure, i.e., largely free of air bubbles. Frazil ice forms in turbulent flows when the water is supercooled [18]. Spherical and irregularly bounded air inclusions are embedded in this type of ice. Snow ice forms when snow falls into cool water (close to $0{ }^{\circ} \mathrm{C}$ ), or when snow on an ice cover gets wet (due to rainfall or elevation of the water level) and then freezes. Snow ice contains small and spherical air bubbles. Finally, consolidated ice is a thick, porous, and rough-surfaced accumulation of ice floes that forms during freeze-up. It may be constituted from a variety of ice types.

\section{B. River Ice Parameters}

During the winter season, the backscattered radar signal from fully frozen ice cover is composed of surface and volume scattering contributions. The surface scattering is influenced by the effective (small-scale) roughness and dielectric 
TABLE I

ClassificAtion ACCORding to [22] OF THE EFFECTIVE Roughness FOR THE AIR-ICE AND ICE-WATER INTERFACES FOR THE RADARSAT-2 WAVELENGTH, AT AN INCIDENCE ANGLE OF $35^{\circ}$, AND ASSUMING AN ICE TEMPERATURE OF $-5{ }^{\circ} \mathrm{C}$. HeIGHT $h$ (IN CENTIMETERS) CORRESPONDS TO THE Standard DEVIATION OF THE SuRface Height IRREGULARITIES (SEE [23])

\begin{tabular}{|c|c|c|c|}
\hline & Smooth & Intermediate & Rough \\
\hline Air-ice interface & $h<0.27$ & $0.27 \leq h \leq 1.54$ & $h>1.54$ \\
\hline Ice-water interface & $h<0.15$ & $0.15 \leq h \leq 0.86$ & $h>0.86$ \\
\hline
\end{tabular}

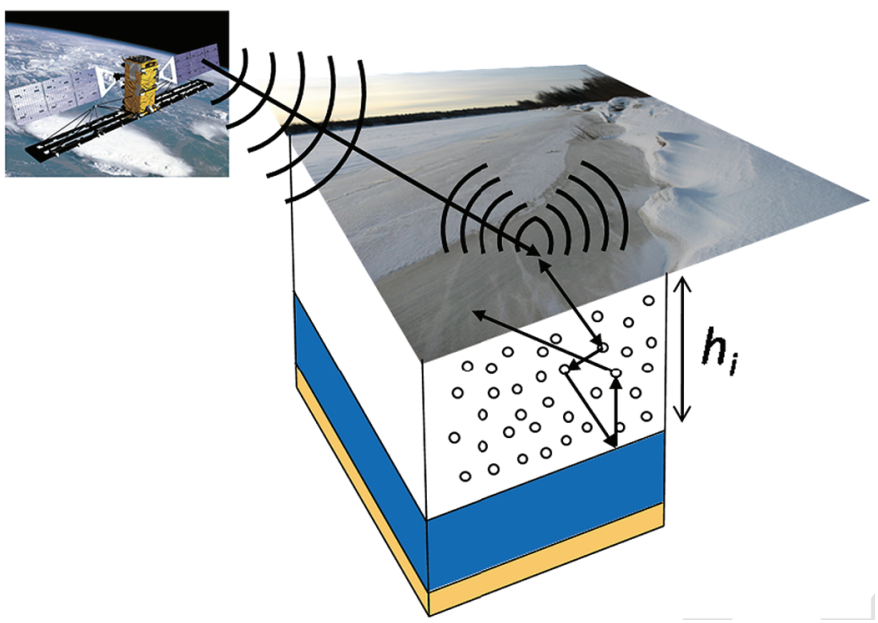

Fig. 1. Thickness $h_{i}$ of a simplified river ice cover, in white, with embedded spherical air inclusions. Water is blue, and ground is brown.

constant of the air-ice and particularly by ice-water interface [19], [20]. The roughness causes depolarization of the incident wave. Table I shows the theoretical boundaries between smooth, intermediate, and rough air-ice and ice-water interfaces of an ice cover imaged by Radarsat- 2 at an incidence angle of $35^{\circ}$. The boundaries are defined in terms of the standard deviation of surface height irregularities ( $h$ in centimeters), which as a rule of thumb, are to be calculated from measurements with a horizontal spacing lower than 0.1 times the wavelength [21]. This roughness classification is based on a modification of the Rayleigh criterion as introduced in [22] and as adapted from [23], [24], but the dielectric constant of ice with embedded air bubbles is lower [25]. Relative to the air-ice interface, the ice-water interface contributes more to overall backscatter due to the large dielectric contrast between the two media (close to 3.17 for ice and 80 for water) [26]. Van der Sanden and Drouin [23] calculate, i.e., based on the approach in [27], that Radarsat-2 waves penetrate pure freshwater ice to about $14 \mathrm{~m}$ (at $-5{ }^{\circ} \mathrm{C}$ and $35^{\circ}$ of incidence angle). The ice-water interface is therefore the dominant scattering surface. A recent study using simulations from electromagnetic modeling has confirmed this [19]. Volume scattering is caused by air bubbles and/or impurities (mineral/organic components such as sediments, stones, and vegetation) embedded in the ice cover. Air inclusions are usually the most significant scatterers [28], depending on their effective size. Fig. 1 illustrates the thickness $h_{i}$ of the ice cover, i.e., the distance between the air-ice and ice-water interfaces. Concerning river ice, ice density $\rho_{i}$ relative to water density (unitless) depends on the amount of air and impurities, which are embedded in the ice and are slightly less than that of pure ice, which is 0.917 . The larger the amount of air, the lower the density of the ice. The density is directly related to the real part of dielectric constant that governs the scattering properties of that medium. An increase in the amount of moisture in river ice cover, e.g., as a result of mild weather, leads to an increase in electromagnetic absorption due to water and thus limits penetration [29] and adversely affects the potential for ice thickness estimation. Similarly, the presence of wet snow cover will obstruct penetration and thus hamper ice cover thickness estimation by means of SAR. Consequently, weather conditions must be monitored to estimate river ice thickness. The thermal conductivity of ice $k_{i}$ is its ability to conduct heat. Thermal conductivity is of no relevance to the radar backscatter, but it is a variable of interest for physical models. At the time of data acquisition, the snow cover overlying the ice was dry, which made it virtually transparent to C-band microwaves [19]. Thus, snow cover is not considered in the analysis.

\section{DATA}

\section{A. Study Site}

The first test site (point 1 in Fig. 2) was the Koksoak River $\left(58^{\circ} 06^{\prime} \mathrm{N} ; 68^{\circ} 24^{\prime} \mathrm{W}\right)$, which is located in northern Quebec (Canada). The Koksoak River begins at the junction of the Melezes and Caniapiscau Rivers and flows for about $130 \mathrm{~km}$ in a northeastern direction to Ungava Bay, passing by the village of Kuujjuaq, which lies about $50 \mathrm{~km}$ from the coast. The study section is $30-\mathrm{km}$-long upstream from Kuujjuaq. Channel width ranges from $400 \mathrm{~m}$ to $3 \mathrm{~km}$ and depth reaches to $2-4 \mathrm{~m}$ in general. The second test site (point 2 in Fig. 2) was the Saint-François River $\left(45^{\circ} 50^{\prime} \mathrm{N} ; 72^{\circ} 22^{\prime} \mathrm{W}\right)$, located in southern Quebec (Canada), upstream from the town of Drummondville. The stream flow is roughly southeast to northwest. The study section is approximately $30 \mathrm{~km}$ long. Channel width varies from 100 to $850 \mathrm{~m}$, and depth reaches from 2 to $4 \mathrm{~m}$ in general. The last test site (point 3 in Fig. 2) was the middle channel of the Mackenzie River $\left(67^{\circ} 45^{\prime} \mathrm{N} ; 133^{\circ} 75^{\prime} \mathrm{W}\right)$, located in the Northwest Territories (Canada), from roughly Point Separation in the south to Oniak island in the north. The Mackenzie River flows north into the Arctic Ocean.

\section{B. SAR Data}

Polarimetric Radarsat-2 images (see Table II) of the SaintFrançois River, the Koksoak River (courtesy of National Institute of research, Quebec, QC, Canada), and the Mackenzie River (courtesy of the Canada Center for Remote Sensing of Natural Resources Canada, Ottawa, ON, Canada) were acquired in February and March 2009. The resolution of the images is $5.2 \mathrm{~m}$ in range and $7.6 \mathrm{~m}$ in azimuth. The scene size is around $27 \times 27 \mathrm{~km}$. The incidence angles of the images range between $27^{\circ}$ and $35^{\circ}$. The difference in incidence angles between the images $\left(<8^{\circ}\right)$ is small enough for a comparison study, in spite of the fact that these differences may slightly 

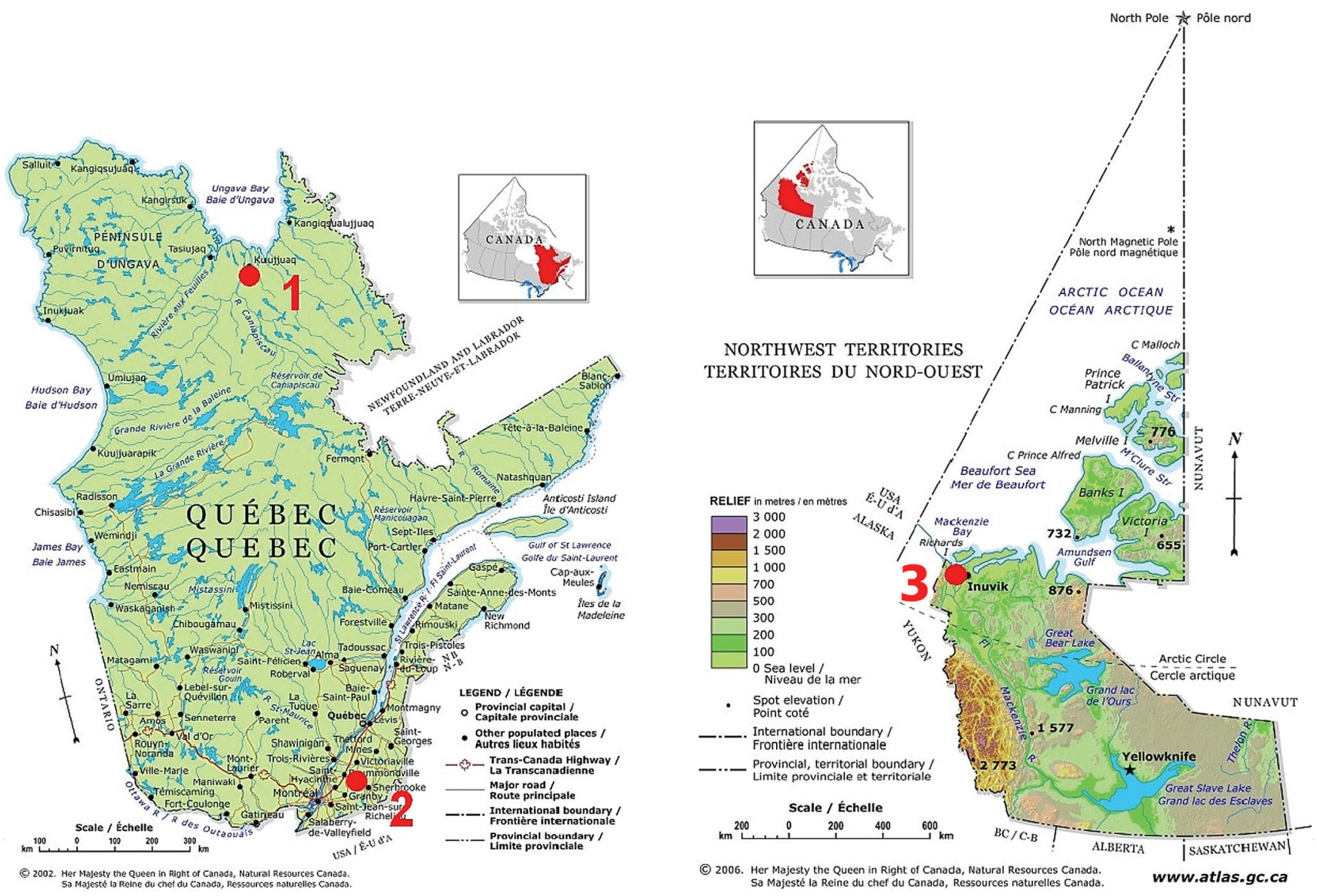

Fig. 2. Locations of the study sites, which are indicated by red dots, in Quebec (left) and the Northwest Territories (right), Canada. In Quebec, point 1 is the Koksoak River, and point 2 is the Saint-François River. In the Northwest Territories, point 3 is the Mackenzie River.

TABLE II

Full-Polarimetric C-BAND SAR DATA ACQUiRed in 2009 By RadARSAT-2. $\boldsymbol{\theta}$ MEANS INCIDENCE ANGLE

\begin{tabular}{|c|c|c|c|}
\hline Date & River & Orbit & $\theta\left(^{\circ}\right)$ \\
\hline 04 Feb. 09-22h34 & St-François & Ascending & 29 \\
\hline 28 Feb. 09-22h34 & St-François & Ascending & 28 \\
\hline 14 Mar. 09-11h05 & St-François & Descending & 28 \\
\hline 07 Mar. 09-11h05 & Koksoak & Descending & 27 \\
\hline 08 Mar. 09-15h36 & Mackenzie & Descending & 35 \\
\hline
\end{tabular}

affect the behavior of the various scattering mechanisms. Images were acquired in descending and ascending modes, which may influence the response of the ice cover surface. However, the acquisition mode did not impact this paper as the ice cover roughness was not orientated in a preferential direction. Polarimetric Radarsat-2 images were supplied in single-look complex (SLC) format and were multilooked (one look in range and two looks in azimuth). Sigma nought convention was used in this paper. A $7 \times 7$ window size Lee filter [30] was applied to reduce the speckle effect. The resulting equivalent number of looks was about 50. A geometric correction process was then applied using a photogrammetric approach [31] in order to get a mean square error (MSE) around 1 pixel. The images were finally resampled to a spatial resolution of $10 \mathrm{~m}$ using the nearest neighbor method.

Polarimetric radar measures the response of a medium in the form of complex scattering components, which is expressed in the $(h, v)$ ( $h$ means horizontal and $v$ means vertical) polarization basis as $S_{h h}, S_{h v}, S_{v h}$, and $S_{v v}$. In the monostatic case, if reciprocity is assumed, $S_{h v}=S_{v h}$. Thus, the polarimetric data set can be represented as a target vector, i.e.,

$$
k_{3}=\left[S_{h h} \sqrt{2} S_{h v} S_{v v}\right]^{t}
$$

where the superscript $t$ denotes the matrix transpose. The $3 \times 3$ covariance matrix $C_{3}$ is defined from this vector as

$$
C_{3}=k_{3} k_{3}^{*^{t}}
$$

where $k_{3}^{*}$ is the complex conjugate of $k_{3}$. Target decomposition theorems can be applied to the covariance matrix for a better understanding of the scattering mechanisms. The decomposition in [16] is based on eigenvalue analysis of the covariance matrix. Each of the three scattering mechanisms, i.e., the so-called odd-bounce (or surface), even-bounce (or doublebounce) and multiple (or volume) scattering, is weighted by its 
pseudoprobability $p_{i}$, corresponding to its relative power with respect to the total power, i.e.,

$$
p_{i}=\frac{\wedge_{i}}{\sum_{i=1}^{3} \wedge_{i}} \quad \sum_{i=1}^{3} p_{i}=1
$$

where $\wedge_{i}$ are the eigenvalues from the diagonalized $C_{3}$ matrix. Entropy $H$ provides a measure of statistical disorder [16], i.e.,

$$
H=-\sum_{i=1}^{3} p_{i} \log _{3}\left(p_{i}\right) \quad 0 \leq H \leq 1
$$

where $\log _{3}$ is the logarithm to the base 3. Alpha angle $\alpha$, which is related to the scattering mechanisms, is defined as [16]

$$
\alpha=\sum_{i=1}^{3} p_{i} \alpha_{i}
$$

where $\alpha_{i}$ angles are extracted from the three components of eigenvectors of the $C_{3}$ matrix. Anisotropy $A_{12}$, which indicates the relative strengths of the first and second scattering mechanisms, is defined from the pseudoprobabilities $p_{1}$ and $p_{2}$ as

$$
A_{12}=\frac{p_{1}-p_{2}}{p_{1}+p_{2}} .
$$

\section{Field Data}

The in situ data were acquired close in time to the Radarsat-2 acquisitions. Ice thickness was determined by means of an ice auger and a measuring tape or estimated using a groundpenetrating radar. To account for the effect of the ice structure on the backscatter coefficient, the ice was also categorized according to type (e.g., thermal, frazil, snow, and/or consolidated) when coring. Basics physical characteristics such as the density and size of air bubbles were also measured. Characterization of air inclusions is useful for understanding river ice thickness estimation errors. On the Saint-François River, ice thickness ranged from 19 to $59 \mathrm{~cm}$ (mean $39 \pm 7.9 \mathrm{~cm}$; 43 samples). On the Koksoak River, the ice thickness ranged from 71 to $87 \mathrm{~cm}$ (mean $81.2 \pm 4.8 \mathrm{~cm} ; 23$ samples). On the Mackenzie River, the ice thickness ranged from 27 to $89 \mathrm{~cm}$ (mean of $72.5 \pm$ $30 \mathrm{~cm}$; 4 samples). In total, 70 thickness samples from three rivers were collected, enabling the development and validation of a new model for river ice thickness estimation. The physical characteristics of the field data are summarized in Table III. On the Saint-François River, the mean ice density was $87.3 \pm 3.3$, and the mean size of air bubbles was $0.74 \pm 0.26 \mathrm{~cm}$. The size of air bubbles embedded in frazil ice from the Koksoak River was measured in small samples. The size of air bubbles embedded in frazil ice was found to be larger on the Koksoak River (mean of $2.25 \pm 0.76 \mathrm{~cm}$ using 11 samples from eight ice cores extracted in 2009 from two sites) than on the SaintFrançois River (mean of $1.37 \pm 0.64 \mathrm{~cm}$ using 55 samples from 37 ice cores extracted in 2008 and 2009 from nine sites). The air-ice interface roughness of the 70 samples was estimated by eye as either intermediate or rough, as defined by the values of $h$ in Table I. The roughness of the ice-water interface, which is affected by water velocity [32], is not available because of the difficulty of measuring velocity directly or indirectly. It should
TABLE III

\begin{tabular}{|c|c|c|c|c|}
\hline River & Ice type & Thickness $(\mathrm{cm})$ & Density $\times 100$ & Bubble size $(\mathrm{cm})$ \\
\hline \multirow{25}{*}{ 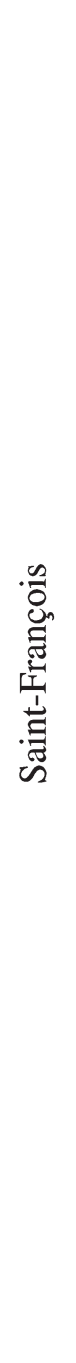 } & Snow & 38 & 75.3 & 0.46 \\
\hline & Snow & 40 & 87.9 & 0.31 \\
\hline & Snow & 52 & 89.8 & 0.43 \\
\hline & Snow & 48 & 86.6 & 0.62 \\
\hline & Thermal & 37 & 87.1 & 0.69 \\
\hline & Thermal & 28 & 88.4 & 1.05 \\
\hline & Thermal & 27 & 88.0 & 0.60 \\
\hline & Frazil & 23 & 88.6 & 0.80 \\
\hline & Thermal & 33 & 82.5 & 0.95 \\
\hline & Thermal & 36 & 87.0 & 0.77 \\
\hline & Thermal & 28 & 88.2 & 0.43 \\
\hline & Thermal & 49 & 88.4 & 0.49 \\
\hline & Thermal & 48 & 89.7 & 0.49 \\
\hline & Thermal & 45 & 88.4 & 0.80 \\
\hline & Frazil & 59 & 88.5 & 0.75 \\
\hline & Frazil & 36 & 87.8 & 0.80 \\
\hline & Frazil & 37 & 89.4 & 0.56 \\
\hline & Thermal & 41 & - & 0.75 \\
\hline & Frazil & 48 & - & 0.95 \\
\hline & Frazil & 52 & - & 1.14 \\
\hline & Frazil & 55 & 89.4 & 0.89 \\
\hline & Frazil & 47 & - & 0.92 \\
\hline & Frazil & 47 & - & - \\
\hline & - & 36 & - & - \\
\hline & - & 42 & 88.6 & 1.40 \\
\hline \multirow{7}{*}{ 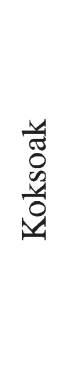 } & Frazil & 36 & - & - \\
\hline & Frazil & 74 & - & - \\
\hline & Frazil & 84 & - & - \\
\hline & Frazil & 74 & - & - \\
\hline & Frazil & 83 & - & - \\
\hline & Frazil & 87 & - & - \\
\hline & Frazil & 71 & - & 1.12 \\
\hline \multirow{4}{*}{ 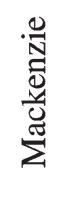 } & Frazil & 27 & - & - \\
\hline & Frazil & 89 & - & - \\
\hline & Frazil & 88 & - & - \\
\hline & Frazil & 86 & - & - \\
\hline
\end{tabular}

PHySicAl DESCRIPTION OF FiEld DATA EXTRACTED OVER SAINT-FRANÇOIS, KOKSOAK, AND MACKENZIE RIVERS IN CANADA

be noted that roughness at the ice-water interface could be a nonnegligible source of errors when retrieving ice thickness from radar data. 

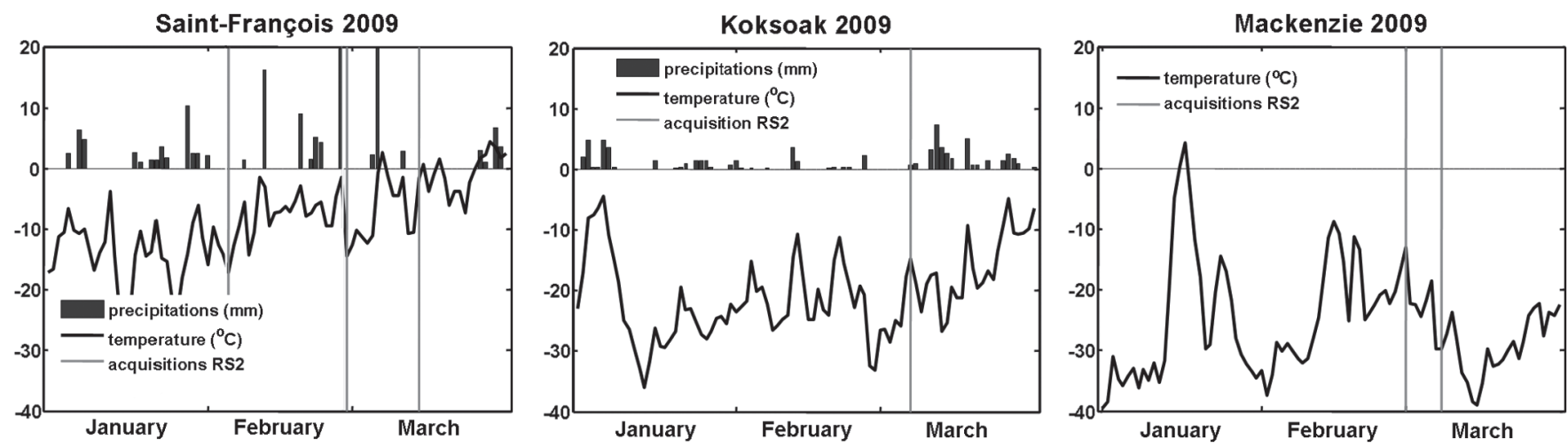

Fig. 3. Mean temperatures (solid line) and precipitation events (vertical bars) measured in 2009 at Drummondville near the Saint-François River, Kuujjuaq near the Koksoak River, and Inuvik near the Mackenzie River, in Canada. Radarsat-2 acquisitions are indicated by vertical solid lines.

\section{Environmental Conditions}

Air temperature, rainfall, snowfall, and wind speed must be monitored since they may affect the backscatter of river ice and thus influence the retrieval of river ice thicknesses. Mean temperatures, rainfalls, and snowfalls measured in 2009 at Drummondville near the Saint-François River, Kuujjuaq near the Koksoak River, and Inuvik near the Mackenzie River are shown in Fig. 3. In the Saint-François area, the air temperature exceeded $0{ }^{\circ} \mathrm{C}$ for a short time between the SAR image acquisitions on February 28 and March 14, but it had returned to below freezing by the time of the second acquisition. No other above freezing temperature anomalies occurred at or close to the SAR image acquisition dates.

The cumulative number of degree days of freezing (CDDF) can explain the presence of frazil and air inclusions in the ice cover. CDDF increases proportionally with the rate of freezing. If ice growth is slow, most of the air will escape back to the water, and the resulting ice will be transparent. Alternatively, if the growth proceeds rapidly, air can be trapped within the ice covers as it forms, creating air intrusions [33]. Gow and Langston [34] investigated the relationship between growth velocity and porosity in thermal lake ice, observing that a greater concentration of air inclusions can generally be linked with rapid freezing. A high rate of freezing is required for frazil formation to occur. CDDF is given by [35]

$$
\mathrm{CDDF}=-\sum_{i=1}^{N} \frac{T_{\max }(i)+T_{\min }(i)}{2}
$$

where $T_{\max }(x)$ and $T_{\min }(x)$ are the maximal and minimal temperatures of the $x$ th day, and $N$ is the number of days. CDDF values for the three sites are presented in Fig. 4. It shows that the Koksoak and Mackenzie rivers experienced similar rapid freezing from early December 2008 until the beginning of March 2009 (90 days from December 1 to March 1 at a mean freezing rate of $\sim 21$ and $\sim 23{ }^{\circ} \mathrm{C}$ per day at the Koksoak River and the Mackenzie River, respectively). In contrast, the Saint-François River experienced slow freezing (90 days from December 1 to March 1 at a mean freezing rate of $\sim 11^{\circ} \mathrm{C}$ per day), leading to a thinner ice cover. The relatively slower rate of freezing on the Saint-François River (where thin ice was predominant) facilitated the release of air back to the water,

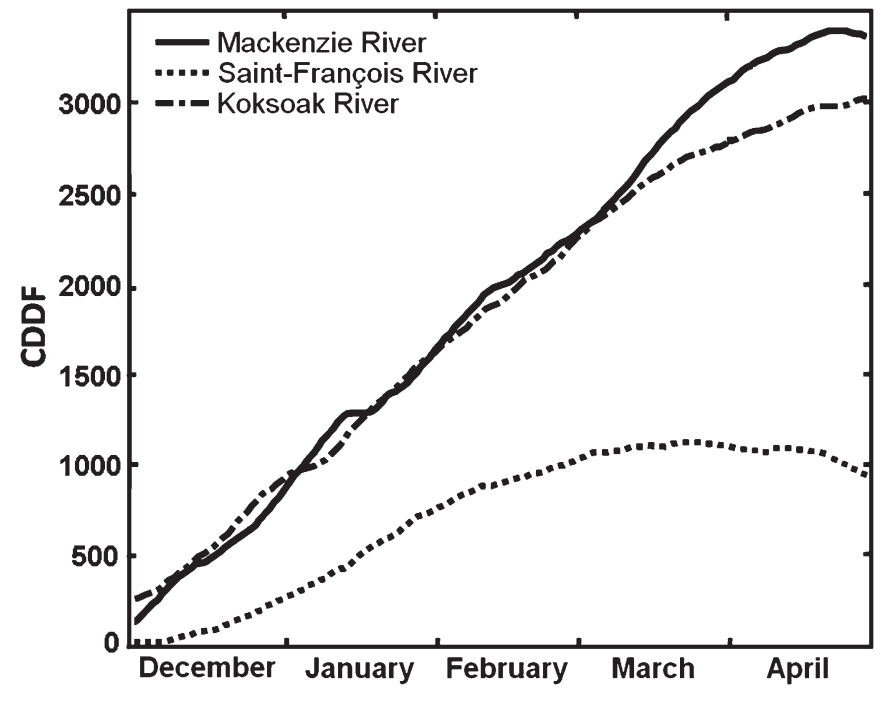

Fig. 4. CDDF measured in 2009 at Drummondville near the Saint-François River, Kuujjuaq near the Koksoak River, and Inuvik near the Mackenzie River, in Canada. CDDF increases proportionally with the rate of freezing. If ice growth proceeds rapidly, air can be trapped within the ice cover as it forms. A high rate of freezing is required for frazil formation to occur.

resulting in correspondingly fewer air inclusions. In contrast, the extended periods of rapid freezing at the Koksoak and Mackenzie rivers (where thick ice was predominant) resulted in a greater quantity of air trapped in the ice cover. The crosssectional diameters of inclusions were also larger, as noted in Section III-C. These physical differences between the ice on the Saint-François River and that on the other rivers made it easier to distinguish between thin ice and thick ice (in terms of electromagnetic response).

\section{Process-Based Ice Models}

Two basic methods of numerical modeling have generally been used to estimate ice thickness: stochastic techniques, which are based on ice records, and deterministic approaches, which are based on physical ice growth and decay principles [36]. Neither type of model produces reliable ice thickness estimates, and both types may require much input, mainly of environmental data [1]-[3]. Neither approach offers spatially distributed ice thickness values and takes the geomorphology 


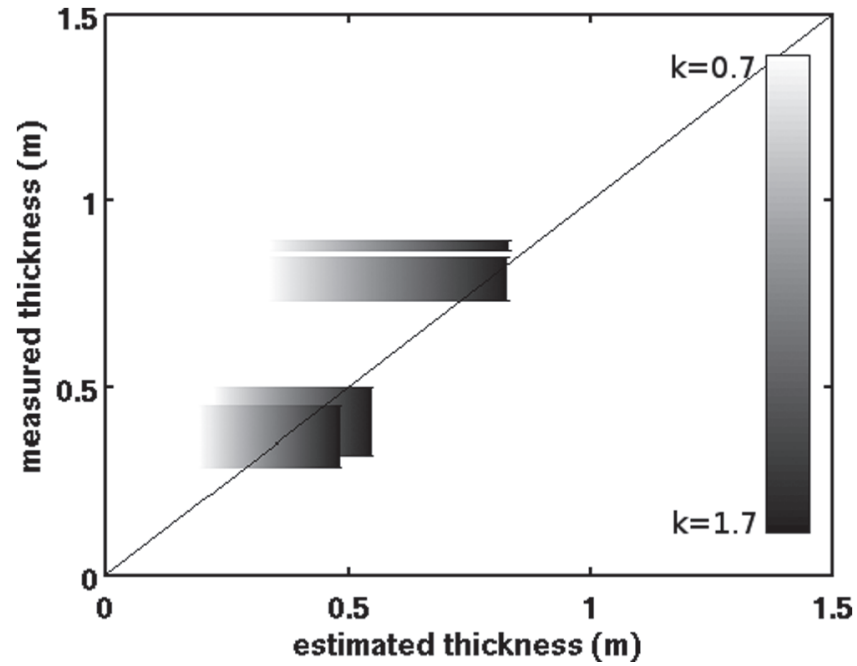

Fig. 5. Comparison of river ice thicknesses estimated with Stefan's model and thicknesses measured in the field, as described in Section III-C. The measured thickness values of the four bars are the means of measured thicknesses for the Saint-François River at two dates (February 3-4 and 25-27, 2009), the Koksoak River (using all samples), and the Mackenzie River (using the three samples with the greatest thickness). The thickness of the bars indicates the standard deviation of the measured ice thickness. The optimal RMSE and relative RMSE are equal to $8.4 \mathrm{~cm}$ and $14.2 \%$, respectively.

of the river into account. Stefan's law [3], which is often used due to its simplicity, gives an ice thickness $h_{i}$ using

$$
h_{i}=\frac{2 k_{i}}{\rho_{i} \lambda_{i}} \sqrt{\mathrm{CDDF}}=k \sqrt{\mathrm{CDDF}}
$$

where $\lambda_{i}$ is the latent heat of ice fusion, and $k$ ranges from 0.7 to 1.4 for narrow rivers with rapid stream flow and from 1.4 to 1.7 for rivers covered by snow. Fig. 5 presents a comparison of river ice thicknesses estimated with Stefan's model and thicknesses that were measured in the field, as described in Section III-C. The measured thickness values of the four bars in Fig. 5 are the means of measured thickness for the Saint-François River on two dates (February 3-4 and 25-27, 2009), for the Koksoak River (using all samples), and for the Mackenzie River (using the three samples with the greatest thickness). The thickness of the bars indicates the standard deviations of the measured ice thickness. The optimal root-mean-square error (RMSE) and relative RMSE ( $\mathrm{RMSE}_{r}$ ) are equal to $8.4 \mathrm{~cm}$ and $14.2 \%$, respectively. Stefan's model appears to offer acceptable estimates of ice thickness regarding these four points. However, the estimation of $k$ is fuzzy because of the difficulty of precisely knowing river ice conditions. Due to the small number of samples used, this example is qualitative only; nevertheless, it illustrates the need for a reliable means of spatially retrieving the thickness of river ice. SAR imagery can provide the data needed for this purpose.

\section{Results}

\section{A. Polarimetric Properties of River Ice}

The main scattering mechanism of river ice is normally surface scattering rather than volume scattering [37], except in the case of consolidated or thick porous ice. As a consequence, $\alpha_{1}$, which represent the nature of the main scattering mechanism, is below $40^{\circ}$. Its pseudoprobability of occurring $p_{1}$ is above 0.7 , and $H$ is lower than 0.5 . This is particularly true when the interfaces of the ice cover are rough, when surface scattering increases, and/or when river ice is pure, leading to low-volume scattering. The radar signal is sensitive to the thickness of an ice cover embedded with air bubbles. When the ice cover becomes thicker, volume scattering tends to increase relative to surface scattering because of the larger number of air bubbles. Angle $\alpha_{1}$ increases, whereas $p_{1}$ decreases, and $H$ becomes higher as both surface scattering and volume scattering occur. Other parameters vary with physical characteristics of the ice, such as $\left|S_{h v}\right|^{2}$, which is sensitive to volume scattering, and $\mid S_{h h}-$ $\left.S_{v v}\right|^{2}$, which is sensitive to double-bounce scattering [38]. The radar signal is almost insensitive to thickness variations in pure ice, except for a slight decrease in backscatter intensity due to attenuation of the signal [19]. The dominant ice-water interface acts as a specular reflector, resulting in small overall backscatter and small variability in terms of scattering mechanisms. For this reason, pure ice is not processed in the method presented here.

The polarimetric properties of river ice were estimated using SAR data and field data described in Section III-B and C, respectively. In the following, river ice is considered thin when ice thickness is less than $60 \mathrm{~cm}$ and thick when ice thickness is more than $60 \mathrm{~cm}$. The thickness of 43 in situ river ice samples from the Saint-François River and one sample from the Mackenzie River is therefore thin (44 plots in total), whereas the thickness of 23 in situ samples from the Koksoak River and three samples from the Mackenzie River is thick (26 plots in total). Thin ice is characterized by values of $\left|S_{h h}\right|^{2}$ around $-12.39 \pm 1.21 \mathrm{~dB}$ and $\left|S_{h v}\right|^{2}$ around $-25.59 \pm 1.57 \mathrm{~dB}$. Furthermore, the surface (mostly the ice-water interface) is the dominant scatterer as $\alpha_{1}$ is very low $\left(4.14 \pm 1.20^{\circ}\right)$ and $p_{1}$ very high $(0.89 \pm 0.03)$, despite the potential presence of air inclusions in the ice matrix and varying values of density measured in the field (see Table III). Entropy $H$ is around $0.36 \pm 0.07$, which confirms the predominance of the surface scattering mechanism over the double bounce scattering mechanism. The low return linked to volume scattering is a result of the weak interactions between radar waves and thin river ice. Thick ice is characterized by values of $\left|S_{h h}\right|^{2}$ and $\left|S_{h v}\right|^{2}$ around $-11.18 \pm 1.36 \mathrm{~dB}$ and $-18.19 \pm 1.49 \mathrm{~dB}$, respectively. Two possible polarimetric behaviors may occur.

- The surface scattering mechanism is predominant. Angle $\alpha_{1}$ is low $\left(<40^{\circ}\right)$ but is higher than the thin ice case. Entropy $H$ is high $(>0.7)$, which indicates that the target is depolarizing because of interactions between waves and air inclusions.

- Volume scattering mechanism is predominant. Angle $\alpha_{1}$ is high $\left(>40^{\circ}\right)$, and entropy $H$ is very high $(>0.9)$.

These values are summarized in Table IV.

\section{B. Development of Direct Model}

Model Relating Radarsat-2 PolSAR Data to River Ice Thickness: The relationships between polarimetric parameters and in situ river ice thickness (70 samples from the Saint-François, Koksoak, and Mackenzie Rivers) were established using statistical regressions. Regression models can take several forms. For 
TABLE IV

Polarimetric Properties of Thin $(<60 \mathrm{~cm})$ AND THick $(>60 \mathrm{~cm})$ River ICE

\begin{tabular}{|c|c|c|c|c|c|}
\hline & $\left|S_{h h}\right|^{2}(\mathbf{d B})$ & $\left|S_{h v}\right|^{2}(\mathbf{d B})$ & $\alpha_{1}\left({ }^{\circ}\right)$ & $p_{1}$ & $H$ \\
\hline \hline Thin ice & $-12.39 \pm 1.21$ & $-25.59 \pm 1.57$ & $4.14 \pm 1.20$ & $0.89 \pm 0.03$ & $0.36 \pm 0.07$ \\
\hline Thick ice & $-11.18 \pm 1.36$ & $-18.19 \pm 1.49$ & $14.70 \pm 16.50$ & $0.65 \pm 0.08$ & $0.78 \pm 0.08$ \\
\hline
\end{tabular}

TABLE V

Best Regression Results Relating Polarimetric Parameters to ICE Thickness, Using 70 Samples From the Saint-François, KOKSOAK, AND MACKENZIE RIVERS

\begin{tabular}{|c|c|c|c|c|c|c|c|c|}
\hline Variable & $H$ & $\alpha$ & $p_{1}$ & $p_{2}$ & $\left|S_{h h}-S_{v v}\right|^{2}$ & $A_{12}$ & $p_{3}$ & $\left|S_{h v}\right|^{2}$ \\
\hline$r_{p}^{2}$ & 0.85 & 0.79 & 0.79 & 0.79 & 0.78 & 0.76 & 0.76 & 0.73 \\
\hline
\end{tabular}

this paper, linear and nonlinear regressions were tested to find the optimal polarimetric parameters. The best regression (using the Pearson coefficient of determination $r_{p}^{2}$ to gauge the fit) was obtained using a second-order polynomial function. The best quantitative results are shown in Table $\mathrm{V}$. The regressions were significant, as $r_{p}^{2}$ varied from 0.73 to 0.85 , and $p$ values were negligible. Regressions and associated 95\% confidence intervals, relating polarimetric parameters to ice thickness, are shown in Fig. 6. Parameters derived from eigenvalue and eigenvector analysis [16], particularly $H$, which provides a measure of statistical disorder, were found to provide the best fit with river ice thickness $\left(r_{p}^{2}\right.$ was 0.85$)$. This was probably due to the fact that $H$ is a function of pseudoprobabilities $p_{1}, p_{2}$, and $p_{3}$, which are related to the relative power of scattering mechanisms sensitive to river ice thickness. The backscattering coefficient $\left|S_{h h}\right|^{2}$ provided a much poorer fit with river ice thickness variations $\left(r_{p}^{2}\right.$ was 0.22 , very similar to the results in [15]), demonstrating the value of using polarimetric data. The regression depending on $H$, which is selected because it gave the best correlation with measured ice thickness, is given by

$$
h_{i}=-0.55 H^{2}+1.57 H-0.09 .
$$

This estimator is valid for C-band data at incidence angles in the range of $27^{\circ}-35^{\circ}$, with $H$ ranging from $\sim 0.20$ to 0.85 . It starts to saturate when ice thickness is up to $0.80 \mathrm{~m}$. The standard deviation values for $H$ in the $5 \times 5$ pixel windows range from $5 \cdot 10^{-3}$ to 0.17 .

Validation of the Direct Model: River ice thickness was retrieved from SAR data using (9), which depends on $H$ alone. Entropy $H$ is a function of pseudoprobabilities that are ratios and hence insensitive to absolute intensities, making the model more adaptable to other images compared with parameters based on the single-polarization intensity. A leave-one-out cross-validation was applied to assess the accuracy of the river ice thickness estimates. A single sample from the observations was used for validation, with the remaining observations used as training data. This method was repeated 70 times, such that each observation was used once for validation. The results are presented in Fig. 7. RMSE was equal to $9.2 \mathrm{~cm}$, and $\mathrm{RMSE}_{r}$ was equal to $16.6 \%$. The level of accuracy obtained was about the same as that of Stefan's model (see Section IV), but the new model using PolSAR data additionally provides spatially explicit ice thickness maps. The standard deviation was greater for thin ice ( $\simeq 7 \mathrm{~cm}$ for Saint-François thickness measures) than for thick ice ( $\simeq 2 \mathrm{~cm}$ for Koksoak thickness measures).

\section{River Ice Thickness of the Saint-François, Koksoak, and Mackenzie Rivers}

The method described in Section V-B was applied to the Radarsat-2 images. This method is not suitable for estimating the thickness of pure thermal ice because the backscattered radar signal is almost insensitive to thickness variations of a pure ice cover. The thickness of consolidated ice also should not be estimated using this method because consolidated ice is very inhomogeneous (i.e., includes many dielectric discontinuities), which causes the waves to be reflected and absorbed before they reach the ice-water interface. The solution that we adopted was to mask out pure thermal ice and consolidated ice. To do so, the radar images were classified according to cover type prior to ice thickness estimation. Wishart classification was chosen as it shows good results for river ice classification [37], [39]. The complex Wishart distribution-based maximum-likelihood classifier calculates distances between a sample covariance matrix (for a pixel) and a cluster mean (for a class) [40]. The distance measure is independent of the number of looks and can be applied to multilook-processed or speckle-filtered PolSAR data. Unlike single-polarization-based techniques, the Wishart algorithm enables classification based on scattering mechanism types [41]. The four classes were defined as open water, pure thermal ice, consolidated ice, and frazil/snow ice. Five hundred samples for each class were selected during the training step. Open water samples were extracted from the Radarsat-2 image acquired on February 4, 2009 over the Saint-François River. Thermal ice samples are extracted from the Radarsat- 2 image acquired at March 7, 2009 over the Koksoak River, whereas consolidated ice and frazil/snow ice samples were extracted from both images. The classification results were evaluated with the help of a confusion matrix. In Table VI, columns show the ice cover type as assigned by the classifier, whereas rows indicate in situ types of ice. The confusion matrix was computed using different training and validation sites. The number of samples used in the validation step was 191, 1996, 5852, and 15689 for the open water, pure thermal ice, consolidated ice, and frazil/snow ice classes, respectively. Mean producer's accuracy (PA) was 99.1\%, mean user's accuracy (UA) was $90.8 \%$, and the Kappa coefficient [42] was 0.97 . For the frazil/snow 

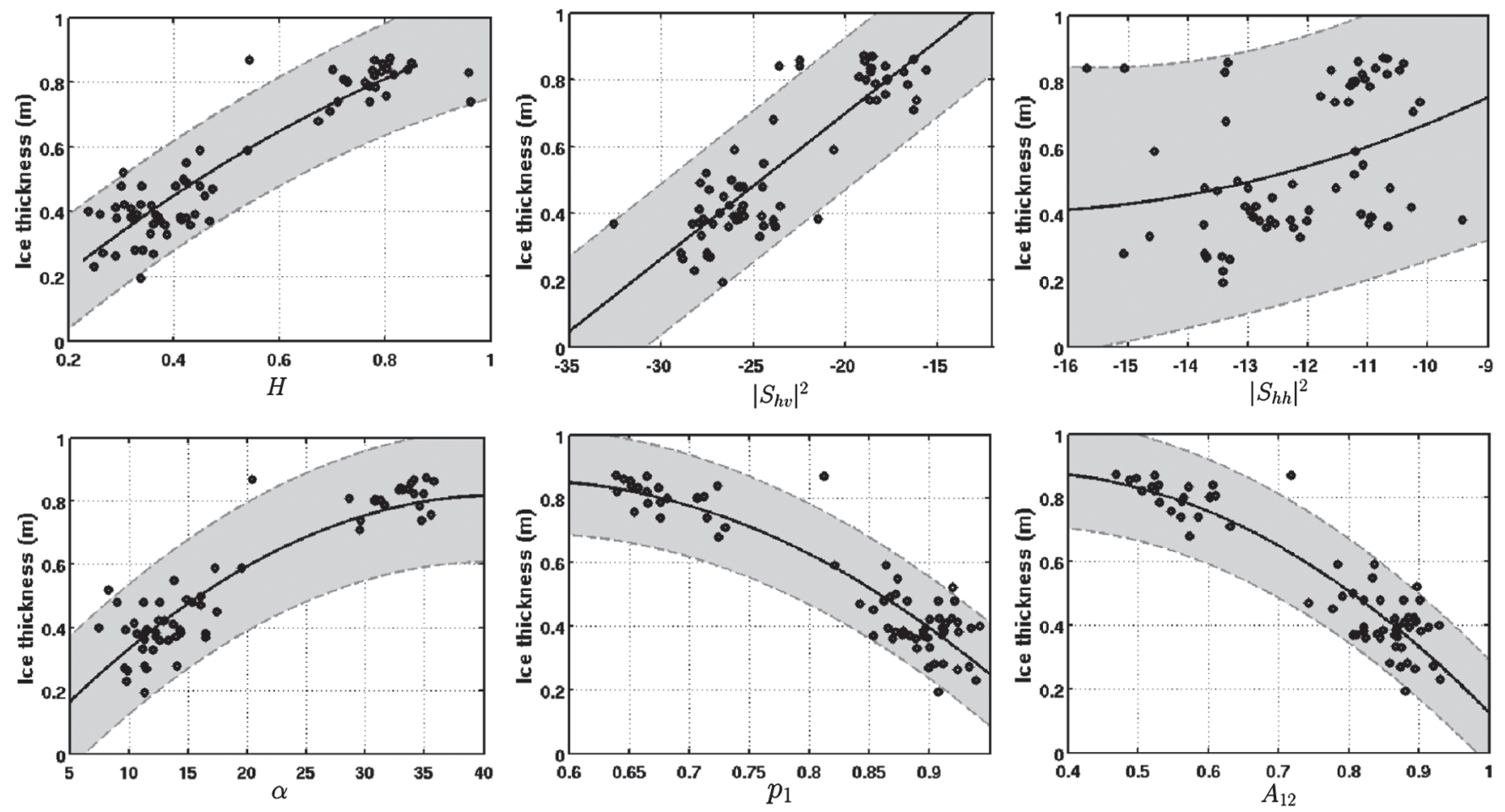

Fig. 6. Regressions (solid lines) relating ice thickness to polarimetric parameters using 70 samples from the Saint-François, Koksoak, and Mackenzie rivers. The dashed lines represent the $95 \%$ confidence interval.

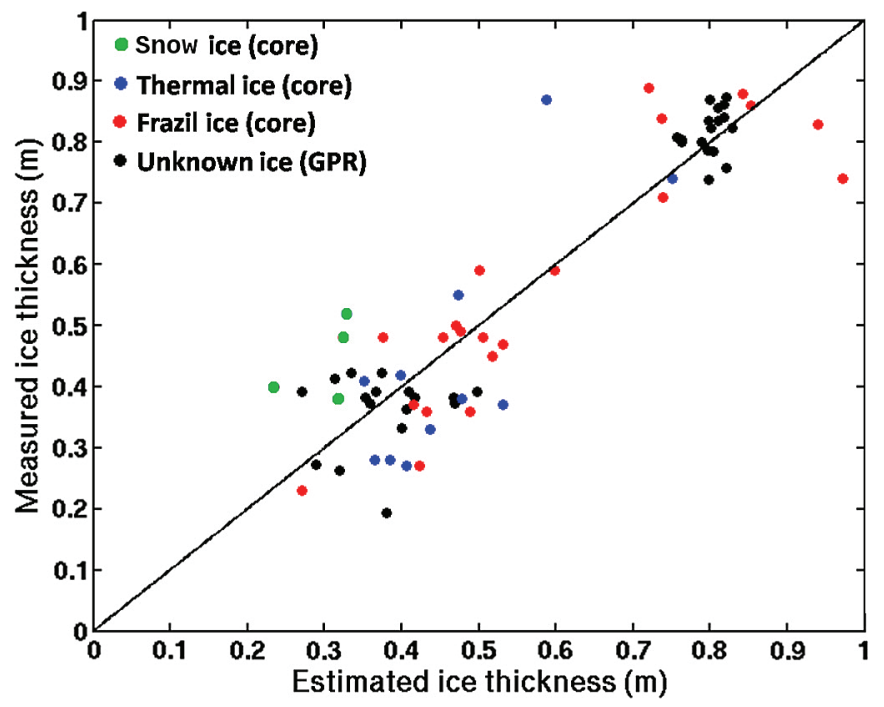

Fig. 7. Quantitative comparison of estimated and measured river ice thickness after leave-one-out cross-validation. RMSE was $9.2 \mathrm{~cm}$, and $\mathrm{RMSE}_{r}$ was $16.6 \%$.

ice class, PA was $98.1 \%$, and UA was $99.8 \%$. Consolidated ice, pure thermal ice, and open water were masked, enabling the thickness of frazil/snow ice to be estimated.

For the Saint-François River, the masked samples represented $29.9 \%, 50.2 \%$, and $52.6 \%$ of the total number of pixels for the data sets acquired on February 4 and 28, and March 14, 2009, respectively, (135342, 141800 , and 99324 pixels). Radarsat-2 data for the unmasked area were inverted on a pixel basis into river ice thickness values using (9). With some exceptions, ice thickness remained fairly constant over time.
Fig. 8 depicts one of the exceptions, a section of the SaintFrançois River where the ice cover grew in thickness during the winter. This part of the river is wide, with weak sinuosity, and the stream flow is calm. Thus, the ice cover remained intact and grew thermally over time. In other rivers, particularly narrow and sinuous rivers with high stream flow, the opposite phenomenon depletion of the ice cover may be observed.

Fig. 9 shows the estimated river ice thickness for the data set acquired on March 7, 2009 over the Koksoak River. The masked samples represented $60.4 \%$ of the total number of pixels (1 057848 pixels). Ice thickness was not spatially constant. Zone a, incorporating the main and secondary channels of the river, was particularly thick. Some pixels probably correspond to ice thicknesses beyond the predictive range of the model, i.e., thicknesses of more than $93 \mathrm{~cm}$. The ice thickness was lower in zones $\mathbf{b}$ and $\mathbf{c}$. The ice in these zones may also have been less porous, leading to underestimation of ice cover thickness. In addition, the ice in some parts of zone $\mathbf{b}$ may have extended all the way to the river bed, resulting in low entropy in the data for those areas. It is important to note that zones $\mathbf{b}$ and c are particularly unstable because of the influence of the tide. Tidal currents can have a significant local effect on river ice; this probably explains the variability in the ice thickness estimates.

The estimated river ice thickness for the data set acquired on March 8, 2009 over the Mackenzie River was uniformly distributed spatially. Some pixels saturated the estimator because of high thickness and/or porosity (see Section V-A).

\section{CONCLUSION}

In this paper, we have developed a methodology for the retrieval of river ice thickness. The method was developed 
TABLE VI

Comparison of the Classification With in Situ Data. Columns Show the ICe Cover Type as Assigned by the Classifier, Whereas Rows Indicate in Situ Types of ICE. Mean Producer ACCuracy (PA) Was 99.1\%, Mean User ACCURACY (UA) WAS 90.8\%, AND THE KAPPA COEFFICIENT [42] WAS 0.97

\begin{tabular}{|c|c|c|c|c|c|c|c|}
\hline & & \multicolumn{5}{|c|}{ Classification } & \multirow[b]{2}{*}{ PA $(\%)$} \\
\hline & & Open Water & Pure thermal ice & Consolidated ice & Frazil/snow ice & $\sum$ & \\
\hline \multirow{7}{*}{ 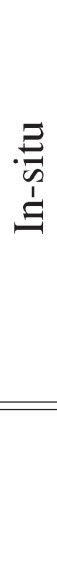 } & Open Water & 191 & 0 & 0 & 0 & 191 & 100 \\
\hline & Pure thermal ice & 0 & 1996 & 0 & 0 & 1996 & 100 \\
\hline & Consolidated ice & 71 & 0 & 5745 & 36 & 5852 & 98.2 \\
\hline & Frazil/snow ice & 6 & 97 & 195 & 15391 & 15689 & 98.1 \\
\hline & $\sum$ & 268 & 2093 & 3547 & 5940 & 15427 & \\
\hline & UA $(\%)$ & 71.3 & 95.4 & 96.7 & 99.8 & & \\
\hline & Карра & 0.97 & & & & & \\
\hline
\end{tabular}

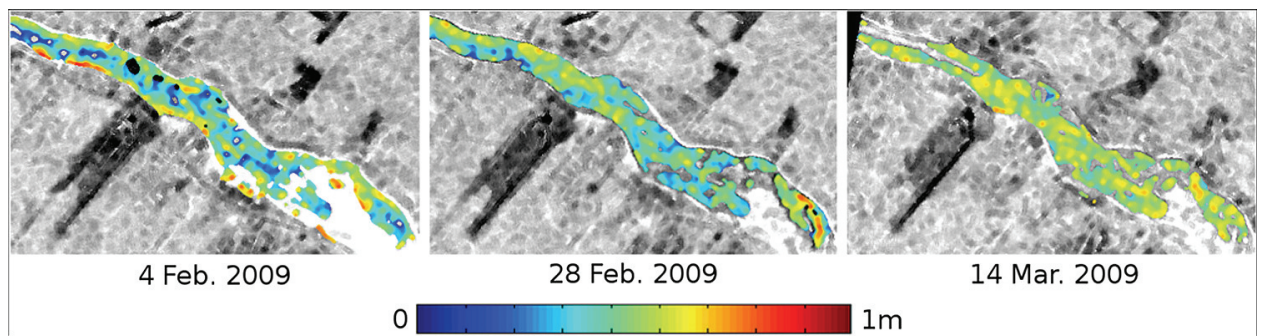

Fig. 8. River ice thickness estimation for a $4 \times 2.8 \mathrm{~km}$ section (location $45.8^{\circ} \mathrm{N} 72.4^{\circ} \mathrm{W}$ ) of the Saint-François River, showing growth of the ice cover during the winter. The total power (span) is in gray levels.

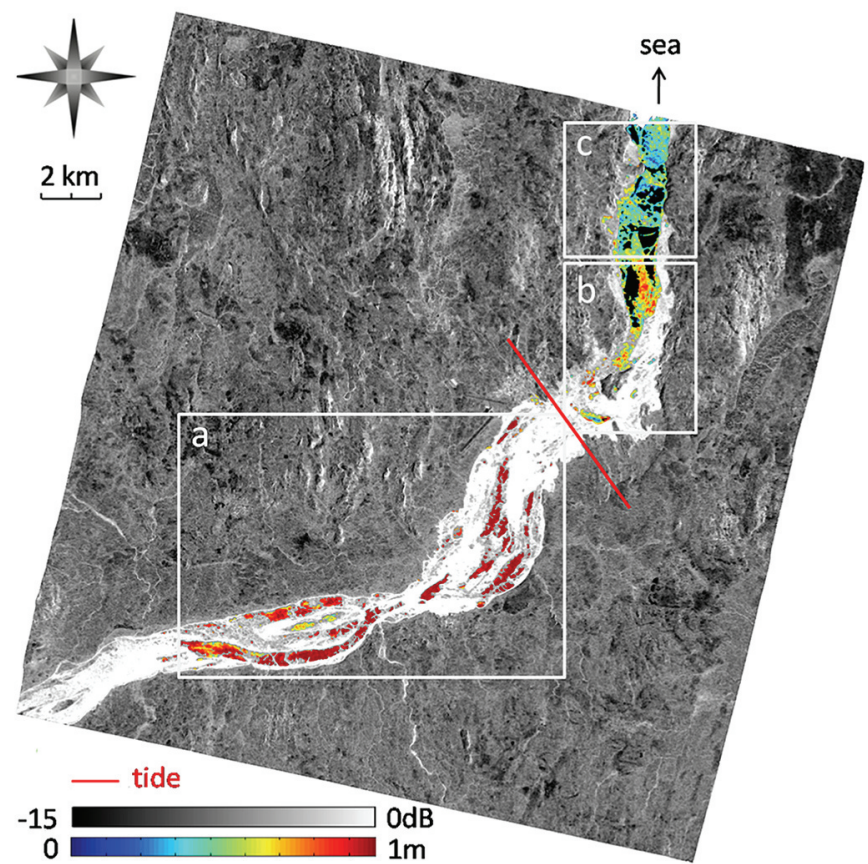

Fig. 9. River ice thickness estimate for the data set acquired on March 7, 2009 over the Koksoak River (the dimensions are $27 \times 27 \mathrm{~km}$ ). The total power (span) is in gray levels. using in situ data (70 samples) and polarimetric C-band SAR data collected by Radarsat- 2 for three rivers in two regions of Canada. Estimates of river ice thickness produced using this method were then applied to generate detailed spatially explicit thickness maps for selected ice types. The different kinds of river ice and the physical reasons behind the detected signal changes were discussed before estimating the specific polarimetric properties of river ice using SAR data and field data. The relationship between the radar data and the river ice data was analyzed. Entropy, which provides a measure of statistical disorder, was found to provide the best fit with river ice thickness (the fitted model explained up to $85 \%$ of the observed variance in ice thickness). This was due to the fact that entropy is a function of pseudoprobabilities related to the relative power of scattering mechanisms sensitive to river ice thickness. Pseudoprobabilities are ratios and hence insensitive to absolute intensities, making the model more easily adaptable to other images than models that use parameters based on the intensity of single-polarization data. A leave-one-out cross-validation was applied to assess the accuracy of the river ice thickness estimates. RMSE was found to be $9.2 \mathrm{~cm}$, and effective RMSE was $16.6 \%$. The Radarsat-2 data were inverted into ice thickness estimates for the three Canadian rivers. Bubble-free thermal ice and consolidated ice (defined using a Wishart classification of 
river ice types) were masked during this procedure. These ice types were excluded because the backscattered radar signal is almost insensitive to thickness variations. In fact, when thermal ice is bubble free, the dominant ice-water interface acts as a specular reflector, resulting in small overall backscatter and small variability in terms of scattering mechanisms. Consolidated ice is very inhomogeneous (i.e., includes many dielectric discontinuities), which causes the waves to be reflected and absorbed before they reach the ice-water interface. The mean PA was $99.1 \%$, the mean UA was $90.8 \%$, and the kappa coefficient was 0.97 . Bubble-free thermal ice and consolidated ice were found to represent surface areas ranging from $29.9 \%$ to $60.4 \%$ of the river, depending on the study site. The robustness of our empirical model and, thus, its potential for application to data sets corresponding to other rivers or winter seasons remain to be assessed. Further studies using interferometric SAR data are promising for the retrieval of pure thermal ice thickness [43].

\section{ACKNOWLEDGMENT}

The authors would like to thank M. H. Drouin, M. Rousseau, Y. Gauthier, Y. Dribault, Ms. J. Noel, and Hydro-Quebec for help with ground data. They would also like to thank I. Gherboudj and Y. Gauthier for many useful conversations about river ice. Anonymous referees provided helpful suggestions and comments.

\section{REFERENCES}

[1] L. Schulyakovskii, Manual of Ice-Formation Forecasting for Rivers and Inland Lakes. Jerusalem, Israel: Israel Program Scientific Translations, 1966.

[2] S. Beltaos, River Ice Jams. Littleton, CO, USA: Water Resource Publ., 1995.

[3] H. Stefan and X. Fang, "Simulated climate change effects on ice and snow covers on lakes in a temperate region," Cold Reg. Sci. Technol., vol. 25, no. 2, pp. 137-152, Mar. 1997.

[4] R. Leconte and P. Klassen, "Lake and river ice investigations in Northern Manitoba using airborne SAR imagery," Arctic, vol. 44, no. 5, pp. 153$163,1991$.

[5] R. Leconte and T. Pultz, "Evaluation of the potential of RADARSAT for flood mapping using simulated satellite SAR imagery," Can. J. Remote Sens., vol. 17, no. 3, pp. 241-249, 1991.

[6] S. Petryk, L. Gatto, T. Prowse, M. Demuth, J. Wuebben, and S. Beltaos, Field Observations and Measurements. Highlands Ranch, CO, USA: Water Resources, 1993.

[7] T. Puestow, C. Randell, K. Rollings, A. Khan, and R. Picco, "Near realtime monitoring of river ice in support of flood forecasting in Eastern Canada: Towards the integration of earth observation technology in flood hazard mitigation," in Proc. IEEE Geosci. Remote Sens., 2004, vol. 4, pp. 2268-2271.

[8] E. Rignot and M. Drinkwater, "Winter sea ice mapping from multiparameter synthetic aperture radar data," J. Glaciol., vol. 40, no. 134, pp. 31-45, 1994.

[9] R. Kwok, S. Nghiem, S. Yueh, and D. Huynh, "Retrieval of thin ice thickness from multi-frequency polarimetric SAR data," Remote Sens. Environ., vol. 51, no. 3, pp. 361-374, Mar. 1995.

[10] T. Matsuoka, S. Uratsuka, M. Satake, A. Nadai, H. Wakabayashi, T. Humehara, H. Maeno, H. Wakabayashi, K. Nakamura, and F. Nishio, "CRL/NASDA airborne SAR (Pi-SAR) observations of sea ice in the sea of Okhotsk," Ann. Glaciol., vol. 33, no. 1, pp. 115-119, Jan. 2001.

[11] R. Drucker, S. Martin, and R. Moritz, "Observations of ice thickness and frazil ice in the St. Lawrence Island polynya from satellite imagery, upward looking sonar, and salinity/temperature moorings," J. Geophys. Res., vol. 108, no. C5, p. 3149, 2003.

[12] C. Duguay and P. Lafleur, "Determining depth and ice thickness of shallow sub-Arctic lakes using space-borne optical and SAR data," Int. J. Remote Sens., vol. 24, no. 3, pp. 475-489, Jan. 2003.
[13] K. Nakamura, H. Wakabayashi, S. Uto, K. Naoki, K. Nishio, and S. Uratsuka, "Sea ice thickness observation in the sea of Okhotsk using ENVISAT/ASAR data," in Proc. IEEE Geosci. Remote Sens., Nov. 2005, vol. 6, pp. 4026-4029.

[14] M. Jasek, F. Weber, and J. Hurley, "Ice thickness and roughness analysis on the Peace River using RADARSAT-1 SAR imagery," in Proc. 12th River Ice Workshop, Committee River Ice Process. Environ. (CGU-HS), 2003 , pp. 50-68.

[15] K. Unterschultz, J. Van Der Sanden, and F. Hicks, "Potential of RADARSAT-1 for the monitoring of river ice: Results of a case study on the Athabasca River at Fort McMurray, Canada," Cold Reg. Sci. Technol., vol. 55, no. 2, pp. 238-248, Feb. 2009.

[16] S. Cloude and E. Pottier, "An entropy based classification scheme for land applications of polarimetric SAR," IEEE Trans. Geosci. Remote Sens., vol. 35, no. 1, pp. 68-78, Jan. 1997.

[17] G. Ashton, River and Lake Ice Engineering. Highlands Ranch, CO, USA: Water Resources Publ., 1986.

[18] S. Daly, "Report on frasil ice," Hydraulics of River Ice. U.S. Army Corps of Engineers, Cold Reg. Res. Eng. Lab., Hanover, Germany, Tech. Rep. 94-23, 1994.

[19] I. Gherboudj, M. Bernier, and R. Leconte, "A backscatter modeling for river ice: Analysis and numerical results," IEEE Trans. Geosci. Remote Sens., vol. 48, no. 4, pp. 1788-1798, Apr. 2010.

[20] M. Bryan and R. Larson, "The study of fresh water lake ice using multiplexed imaging radar," J. Glaciol., vol. 14, no. 72, pp. 445-457, 1975.

[21] F. T. Ulaby, R. K. Moore, and A. K. Fung, Microwave Remote Sensing Active and Passive-Volume II: Radar Remote Sensing and Surface Scattering and Emission Theory. Reading, MA, USA: Addison-Wesley, 1982, ser. Advanced Book Program.

[22] W. Peake and T. Oliver, "The response of terrestrial surfaces at microwave frequencies," Ohio State Univ., Electroscience Lab., Columbus, OH, USA, Tech. Rep. AFAL-TR-70-301, 1971.

[23] J. van der Sanden and H. Drouin, "Satellite SAR observations of river ice cover: A RADARSAT-2 (C-band) and ALOS PALSAR (L-band) comparison," in Proc. 16th Workshop Hydraulics Ice Covered Rivers. CGU HS/CRIPE, Winnipeg, MB, Canada, 2011, pp. 179-197.

[24] S. Evans, "The dielectric properties of ice and snow-A review," $J$. Glaciol., vol. 5, pp. 773-792, 1965.

[25] D. Cooper, R. Mueller, and R. Schertler, "Remote profiling of lake ice using an S-band short-pulse radar aboard an all-terrain vehicle," Radio Sci., vol. 11, no. 4, pp. 375-381, Apr. 1976.

[26] C. Elachi, M. L. Bryan, and W. F. Weeks, "Imaging radar observations of frozen arctic lakes," Remote Sens. Environ., vol. 5, pp. 169-175, 1976.

[27] C. Matzler and U. Wegmuller, "Dielectric properties of freshwater ice at microwave frequencies," J. Phys. D, Appl. Phys., vol. 20, no. 12, pp. 1623-1630, Dec. 1987

[28] B. Michel and M. Drouin, Formation, Classification et Proprietes Mecaniques de la Glace: Sixieme Colloque D'initiation Aux Principes de l'hydrologie. Sainte-Foy, QC, Canada: Univ. Laval, 1972, ser. Report GCE-72-08-01, p. 18.

[29] M. Drinkwater, "Ice surface characteristics: Implications for C-band sar backscatter signatures," IEEE Trans. Geosci. Remote Sens., vol. 27, no. 5, pp. 501-513, Sep. 1989.

[30] J. Lee, M. Grunes, and G. de Grandi, "Polarimetric SAR speckle filtering and its implication for classification," IEEE Trans. Geosci. Remote Sens., vol. 37, no. 5, pp. 2363-2373, Sep. 1999.

[31] R. Caloz and C. Collet, Traitements numeriques d'images de teledetection. Montreal, QC, Canada: Presses de l'Univ. Quebec/AUF, 2001.

[32] B. Michel, "Winter regime of rivers and lakes," Corps Eng., U.S. Army, Hanover, NH, USA, Tech. Rep., 1971.

[33] B. Michel and R. Ramseier, Classification of River and Lake Ice Based on Its Genesis, Structure and Texture. Sainte-Foy, QC, Canada: Dept. Civil Eng., Section Ice Mechanic, Univ. Laval, 1969, ser. Report S-15, p. 40.

[34] A. Gow and D. Langston, "Growth history of lake ice in relation to its stratigraphic crystalline and mechanical structure," CRRL Rep., U.S Army Cold Reg. Res. Eng. Lab., Hanover, NH, USA, Tech. Rep., 1977.

[35] K. Burn, "Action du gel sur les fondations," Digest de la Construction au Canada, National Research Council Canada. Division of Building Research, Tech. Rep. CBD-182F, 1977.

[36] K. Chokmani, B. Khalil, T. Ouarda, and R. Bourdages, "Estimation of river ice thickness using artificial neural networks," in Proc. 14th Workshop Hydraulics Ice Covered Rivers. CGU HS/CRIPE, Québec, QC, Canada, 2007, p. 12.

[37] S. Mermoz, S. Allain, M. Bernier, E. Pottier, and I. Gherboudj, "Classification of river ice using polarimetric SAR data," Can. J. Remote Sens. vol. 35 , no. 5 , pp. $460-473$, Oct. 2009. 
[38] W. Cameron and L. Leung, "Feature motivated polarization scattering matrix decomposition," in Proc. Rec. IEEE Int. Radar Conf., May 1990, pp. 549-557.

[39] S. Mermoz, "Contribution de la polarimetrie radar pour l'analyse de la glace de riviere," Ph.D. dissertation, Inst. Nat. Recherche Scientifique (Canada), Quebec City, QC, Canada, 2010.

[40] J. Lee, K. Hoppel, S. Mango, and A. Miller, "Intensity and phase statistics of multilook polarimetric and interferometric SAR imagery," IEEE Trans. Geosci. Remote Sens., vol. 32, no. 5, pp. 1017-1028, Sep. 1994.

[41] Y. Gauthier, F. Weber, S. Savary, M. Jasek, L. Paquet, and M. Bernier, "A combined classification scheme to characterize river ice from SAR data," In EARSeL, eProc., vol. 5, no. 1, pp. 77-88, Feb. 2006.

[42] J. Landis and G. Koch, "The measurement categorical data," Biometrics, vol. 33, pp. 159-174, 1977.

[43] U. Wegmuller, M. Santoro, C. Werner, T. Strozzi, and A. Wiesmann, "Estimation of ice thickness of tundra lakes using ERS-ENVISAT crossinterferometry," in Proc. IEEE IGARSS, Jul. 2010, pp. 316-319.

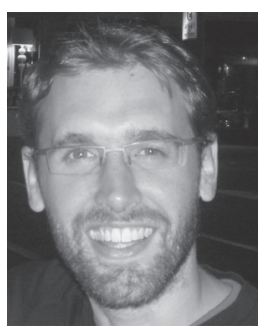

Stephane Mermoz received the Diploma in engineering and the M.Sc. degree in signal processing and telecommunications from the University of Rennes 1, Rennes, France, and the Ph.D. degree from the National Institute of Scientific Research, Quebec, QC, Canada, and the University of Rennes 1 in 2010, with a thesis on remote sensing of river ice in Canada using polarimetric radar data.

In 2011, he received a postdoctoral grant from the National Centre for Space Studies (CNES) to carry out research works at the Center for the Study of the Biosphere from Space (CESBIO) in the frame of supporting activities for the biomass mission as a Postdoctoral Researcher. He is currently working on the development of methodologies to assess above-ground biomass using polarimetric synthetic aperture radar data. $\mathrm{He}$ is also participating in the Reducing Emissions from Deforestation and Degradation in Africa (REDDAF) project.

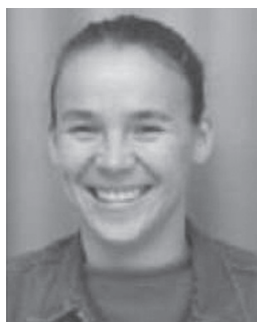

Sophie Allain-Bailhache received the Ph.D. degree in signal processing and telecommunication from the University of Rennes 1, Rennes, France, in 2003.

She is currently an Associate Professor with the University of Rennes 1 and with the Radar Polarimetry Remote Sensing Group, Institute of Electronics and Telecommunications of Rennes, Rennes. Her main research interests include synthetic aperture radar (SAR) polarimetry theory, natural media microwave remote sensing, polarimetric electromagnetic scattering models, analog electronics, digital communications, microwave theory, and polarimetric SAR remote sensing.

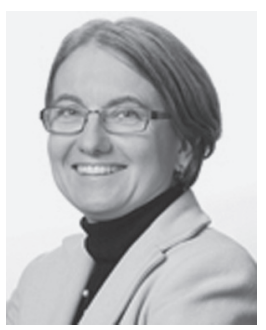

Monique Bernier (M'95-SM'06) received the B.Sc and M.Sc. degrees in physical geography from the University of Sherbrooke, Sherbrooke, QC, Canada, in 1978 and 1980, respectively; the Diploma in business administration from the University of Ottawa, Ottawa, ON, Canada, in 1987; and the Ph.D. degree in water science from the National Institute of Scientific Research (INRS), Québec, QC, in 1991.

In 1981, she started her career in remote sensing as an Environmental Scientist with the Canada Center for Remote Sensing, Ottawa, ON, Canada. From 2008 to 2012, she was a Codirector of a multiinstitutional research center on northern studies. She explored the capability of the Thematic Mapper Landsat and SPOT High-Resolution Visible data for land use and crop mapping. Since 1993, she has been a Professor with the Research Center on Water, Earth, and Environment, INRS. She has developed research partnerships in Canada, Argentina, Ivory Coast, France, Germany, the United States, and Vietnam. She is involved in Network of Excellent Centers such as ArcticNet and WESNet. She is the author of more than 65 papers in refereed journals and has presented in more than 250 conferences in Canadian and International symposia and workshops. Her research include development of applications for synthetic aperture radar (SAR) sensors in water sciences and in Nordic environment (snow, river ice, frost ground monitoring, wetlands, and inundation), and the potential of SAR data to monitor soil moisture in the Mediterranean region and to estimate the wind energy in coastal environment.
Dr. Bernier has been involved in the organization of many Canadian and international symposia. She has been the General Chair of the 1997 Scientific Days in Remote Sensing of Agence Universitaire de la Francophonie, the General Cochair of the 23rd Canadian Symposium on Remote Sensing and Quebec Remote Sensing Association (AQT) Congress, a Technical Program Committee Member of the 2002 International Geoscience and Remote Sensing Symposium (IGARSS)/24th Canadian Symposium on Remote Sensing (CSRS), the Technical Program Cochair of the 28th CSRS/ASPRS 2007 Fall Conference, a Technical Program Committee Member of the 29th CSRS/Tenth Circumpolar RS Conference, the Technical Program Chair of the 2008 Association Francophone pour le Savoir, the Technical Program Committee Member of the 25th CSRS and AQT Congress, the General Cochair of the 32nd CSRS and 16th AQT Congress, the Technical Program Committee Member of the 34th CSRS, and the General Chair of the IGARSS'14 and 35th CSRS. She is the President of the Canadian Remote Sensing Society and the Vice-President of the Association of Canadian Universities for Northern Studies. She is also an Associate Editor for the IEEE JOURNAL OF SELECTED TOPICS IN EARTH ObSERVATIOns And Remote Sensing. In 2011, she received the Ferdinand Bonn Award from the AQT for her significant contribution to the development of SAR data applications in Canada and the formation of scientists.

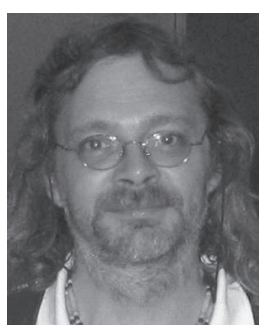

Eric Pottier (M'95-SM'06-F'11) received the M.Sc. and Ph.D. degrees in signal processing and telecommunication from the University of Rennes 1, Rennes, France, in 1987 and 1990, respectively, and the Habilitation from the University of Nantes, Nantes, France, in 1998.

Since 1999, he has been a Full Professor with the University of Rennes 1, Rennes, where he is currently the Director of the Institute of Electronics and Telecommunications of Rennes. He is the author of ten book chapters and more than 60 papers in refereed journals and has presented more than 350 papers during international conferences, symposia, and workshops. He is the coauthor of Polarimetric Radar Imaging: From Basics to Applications (CRC Press, 2009). He has presented advances courses and seminars on radar polarimetry to a wide range of organizations and events. His research interests include analog electronics, microwave theory and radar imaging with emphasis in radar polarimetry, radar image processing (synthetic aperture radar (SAR) and inverse SAR), polarimetric scattering modeling, supervised/unsupervised polarimetric segmentation and classification to fundamentals, and basic theory of polarimetry.

Dr. Pottier received the Best Paper Award at the Third European Conference on Synthetic Aperture Radar (EUSAR 2000) and received the 2007 IEEE Geoscience and Remote Sensing Letters (GRS-S) Prize Paper Award, the 2007 IEEE GRS-S Education Award in recognition of his significant educational contributions to geoscience and remote sensing, and the 2012 Einstein Professorship from the Chinese Academy of Science.

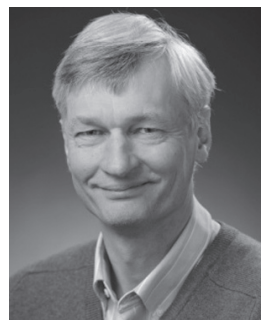

Joost J. Van Der Sanden received the B.S., M.S., and Ph.D. degrees from Wageningen University, Wageningen, Netherlands, in 1984, 1987, and 1997, in forestry and (radar) remote sensing, and the M.S. degree from the University of Aberdeen, Aberdeen, U.K, in 1988 .

$\mathrm{He}$ is currently a Research Scientist with the Canada Centre of Remote Sensing, Natural Resources Canada, Ottawa, ON, Canada. His research focuses on the development of applications for radar remote sensing in cryosphere, coastal, and forest

environments.

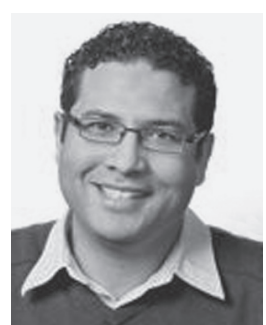

Karem Chokmani received the B.Sc. degree in agricultural engineering from the National Institute of Agronomy of Tunisia, Mahrajène, Tunisia, and the M.Sc. degree in agricultural engineering and the $\mathrm{Ph} . \mathrm{D}$. degree in geomatics from Laval University, Quebec, QC, Canada.

Since 2002, he has been with the INRS University, Quebec, QC, Canada, where he is currently a Professor of remote sensing and statistical hydrology. $\mathrm{He}$ has worked on the development of remote sensing applications for spatiotemporal monitoring of water resources in a climatic change context and on the development of statistical tools for the local and regional estimation of hydrological variables. 